\title{
SOME PHARMACOLOGICAL ACTIONS OF COTTON DUST AND OTHER VEGETABLE DUSTS
}

\author{
BY \\ P. J. NICHOLLS \\ From Welsh School of Pharmacy, Welsh College of Advanced Technology, Cathays Park, Cardiff
}

(RECEIVED FOR PUBLICATION SEPTEMBER 8, 1961)

\begin{abstract}
Aqueous extracts of cotton and other vegetable dusts cause contraction of the isolated ileum and tracheal muscle of the guinea-pig, and of isolated human bronchial muscle. The levels of this contractor activity place the dusts of cotton, flax, and jute in the order of the probable incidence of byssinosis occurring in the mills spinning these fibres.

Extracts of cotton dust possess a histamine-liberating activity and contain a permeabilityincreasing component. These actions are of plant origin and are found in the pericarp and bracts of the cotton boll. Histamine and 5-hydroxytryptamine have also been found in some cotton dust samples. The formation of histamine by bacterial action in cotton dust does not take place under conditions found in cotton mills. The smooth muscle contractor substance is organic in nature, relatively heat-stable, and dialysable. The relevance of these results to the symptoms of byssinosis is discussed.
\end{abstract}

Tests of respiratory function of card-room operatives in a cotton mill suggested the presence of a pharmacologically active agent in the cotton dust which was responsible for the dyspnoea of byssinosis (McKerrow, McDermott, Gilson, and Schilling, 1958), and recent experimental work has shown that the dust possesses biological activity. Antweiler (1960) and Bouhuys, Lindell, and Lundin (1960) have described the presence of a histamine-liberating substance in aqueous extracts of the dust. This activity has been attributed to the endotoxins liberated from the bacterial debris contained in the dust (Pernis, Vigliani, Cavagna, and Finulli, 1961). More recently Davenport and Paton (1962) have shown that cotton dust contains a smooth muscle contractor substance. These authors were unable to detect any significant histamine-liberating action of such extracts, but they observed that, on intravenous injection into guinea-pigs, extracts of the dust liberated a bronchoconstrictor substance which was not histamine. In the work described below the pharmacological study of cotton dust has been extended and the activity of certain other vegetable dusts examined.

\section{METHODS \\ Dust Samples}

The cotton dusts were collected in relation to epidemiological studies that were made in various mills. Samples were obtained from those parts of the mill, mixing room, blow-room, and card-room, in which the symptoms of byssinosis are most prevalent among the workers. In these areas the cotton fibre is separated from plant debris and the operations are accompanied by the production of much dust. Similarly in jute, flax, and hemp mills the process splitting the material into fibres produces a large amount of dust. Only in a few cases were airborne samples used; the remainder were collected from dust which had settled or lay under the carding machines. Unless specifically mentioned the dusts listed below were not airborne samples.

Airborne dusts were collected by the card-room extraction plant from two English cotton mills (samples $E$ and $M$ ), both spinning a coarse grade of cotton. The letters $E$ and $M$ denoting these mills are identical with those employed by Davenport and Paton (1962) who have also examined dusts from these mills. A sample of airborne dust from a Dutch cotton mill was obtained, which had been tested by Antweiler (1960). Dusts from the card-rooms of jute, flax, and hemp mills were collected. Material from underneath the carding machines was 
obtained from an American cotton mill and from the Dutch mill. These two samples consisted of a mixture of cotton cellulose dust and large shreds of the cotton plant debris.

Various dusts were obtained from African mills: the dust from the blow-room of a textile mill spinning a medium staple fibre was composed of much plant material and granular particles that appeared to be soil; from a cotton mill spinning a long staple fibre; and from the opening machine of a sisal mill.

Cotton bolls obtained from Africa were separated into their constituent parts, i.e. the stem of the boll, the bracts, the pericarp, the seeds, and the cotton linters.

\section{Extraction}

Extracts of the dusts were prepared by grinding $5 \mathrm{~g}$. of the material with $20 \mathrm{ml}$. of either distilled water, saline $(0.9 \% \mathrm{w} / \mathrm{v})$, Krebs' solution, or Tyrode's solution, in the presence of acid-washed sand in a mortar for 15 minutes. The fractions of the cotton boll were mechanically reduced to a powder before extraction. The extracts were separated from insoluble matter by squeezing through muslin and were centrifuged at $3,100 \mathrm{G}$. for 30 minutes when a clear but slightly viscous solution resulted.

\section{Chemical Methods}

Nitrogen was estimated by the micro-Kjeldahl method, potassium by flame photometry, and carbohydrate by the method of Ashwell (1957).

\section{Pharmacological Methods}

Most of the pharmacological preparations described are commonly used to detect smooth muscle contractor activity and histamine release.

\section{In vitro Experiments}

(a) Tissue Bath Preparations.-The following preparations were mounted in tissue baths: the isolated duodenum and ileum of the guinea-pig in Tyrode's solution at $37^{\circ} \mathrm{C}$.; the guinea-pig's tracheal muscle preparation as described by Davenport and Paton (1962); isolated human bronchial muscle in Ringer's solution (Hawkins and Schild, 1951); the isolated duodenum, ileum, colon, and uterus of the rat bathed in de Jalon's solution at $31^{\circ} \mathrm{C}$. (Gaddum and Horton, 1959); the isolated duodenum and ileum of the rabbit in Tyrode's solution at $37^{\circ} \mathrm{C}$.; the frog's rectus abdominis muscle in Ringer's frog saline; isolated auricles from guinea-pigs and rabbits in Locke's solution at $29^{\circ} \mathrm{C}$.

(b) Perfused Preparations.-The isolated heart of the guinea-pig was perfused through the aorta with Locke's solution. The guinea-pig's lung was perfused according to the method of Arunlakshana and Schild (1959). For this preparation the lungs are removed from the animal and perfused with Tyrode's solution through the pulmonary artery. The bronchial tree is perfused with air delivered at constant pressure to the trachea. Air escapes through scarifications in the lungs made with the point of a fine needle and changes of pressure in the bronchi are indicated on a manometer connected to the air-perfusion circuit. Drugs are injected into the pulmonary artery. The hind-quarters of the rat were perfused through the abdominal aorta with Tyrode's solution (Feldberg and Mongar, 1954).

\section{In vivo Experiments}

The carotid blood pressure was recorded in rats anaesthetized with pentobarbitone sodium $(40 \mathrm{mg} . / \mathrm{kg}$. intraperitoneally), in rabbits anaesthetized with $25 \%$ urethane (4 to $6 \mathrm{ml} . / \mathrm{kg}$. subcutaneously), and in cats anaesthetized with chloralose (60 mg./kg. intravenously). Injections of cotton dust extracts were made into the contralateral external jugular vein.

The action of dust extracts on intracutaneous injection into the dorsal skin of the guinea-pig was examined using the method of Miles and Miles (1952). This test measures an increase in permeability of the skin capillaries at the site of injection.

The action of extracts was also observed on the forearm of six volunteers, none of whom had previously been exposed to dust. The extracts were sterilized by filtration through a Seitz filter and drops of these were then placed for one minute on scratches on the skin made with a cutting needle. The cutaneous reaction was compared with the reactions to saline and histamine $(0 \cdot 1,0.01$, and $0.001 \%$ ).

Histamine release was investigated by administration of the extracts by intraperitoneal injection in rats and examination of the peritoneal fluid 30 minutes later for the presence of histamine (Fawcett, 1954).

Ten guinea-pigs were exposed in a chamber for one hour per day for six days to an aerosol of an aqueous extract of cotton dust (sample E). The animals were observed for signs of respiratory distress throughout the period of exposure to the aerosol and for a further hour.

Other methods employed are described under Results.

\section{RESULTS}

The aqueous extracts of three dusts and the pericarp of the cotton boll made at room temperature were examined. The results are presented in Table 1. As the cotton linters are almost entirely composed of cellulose it is most probable that the constituents of the aqueous extracts are derived from the other parts of the cotton plant which are present as fragments in the dust. Because the levels of potassium were rather high, which would be expected from a plant source, the effects of a potassium solution of equivalent strength to that of the extracts were always examined for pharmacological actions.

\section{Pharmacological Actions}

\section{In vitro Experiments}

(a) Tissue Bath Preparations.-All the extracts except those of the linters and cotton seeds caused contraction of the isolated ileum of the guinea-pig 
TABLE 1

CHEMICAL ANALYSIS AND PHARMACOLOGICAL ASSAY OF ACTIVITY OF VARIOUS DUST EXTRACTS

\begin{tabular}{|c|c|c|c|c|c|}
\hline \multirow{2}{*}{ Extract* } & \multicolumn{3}{|c|}{ Chemical Analysis } & \multicolumn{2}{|c|}{$\begin{array}{c}\text { Histamine Activity (mg.) (mean } \pm \text { S.E.) } \\
\text { Assayed On }\end{array}$} \\
\hline & $\begin{array}{l}\text { Nitrogen } \\
\text { (mg.) }\end{array}$ & $\begin{array}{c}\text { Carbohydrate } \\
\text { (mg.) }\end{array}$ & $\begin{array}{c}\text { Potassium } \\
\text { (mg.) }\end{array}$ & Ileum $\dagger$ & $\begin{array}{l}\text { Trachea } \S \text { of } \\
\text { Guinea-pig }\end{array}$ \\
\hline $\begin{array}{l}\text { Cotton } \\
\text { Dutch } \\
\text { American } \\
\text { Textile } \\
\text { English M } \\
\text { English E } \\
\text { Long staple fibre } \\
\text { Pericarp } \\
\text { Stem } \\
\text { Bract } \\
\text { Flax } \\
\text { Hemp } \\
\text { Sisal } \\
\text { Jute }\end{array}$ & $\begin{array}{l}4.0 \\
3.4\end{array}$ & $\begin{array}{l}21 \\
55\end{array}$ & $\begin{array}{r}6.0 \\
15.0\end{array}$ & $\begin{array}{l}3 \cdot 6,0.9 \\
3.4,1 \cdot 1 \\
3 \cdot 2,1 \cdot 5 \\
3.1,0.1 \\
2 \cdot 5,0 \cdot 7 \\
1 \cdot 5 \ddagger \\
3 \cdot 1,1 \cdot 8 \\
3.1 \pm \\
1.9,1 \cdot 7 \\
2 \cdot 0,1 \cdot 0 \\
1 \cdot 8,1 \cdot 2 \\
1 \cdot 6,0.7 \\
0.5,0.4\end{array}$ & $\begin{array}{l}32 \cdot 3,11 \cdot 2 \\
35 \cdot 0,16 \cdot 5 \\
24 \cdot 0,13 \cdot 2 \\
18 \cdot 6,14 \cdot 1 \\
13 \cdot 2, \quad 7 \cdot 0\end{array}$ \\
\hline
\end{tabular}

when added to the tissue bath. The contraction was similar in speed of onset and duration to that produced by histamine, although occasionally only a slow contraction was obtained with extracts of jute dust. This is different from the result obtained by Antweiler (1960) who observed that on the addition of an extract to the bath there was a rapid contraction of the ileum followed by a slowly developing increase in tone evident over several minutes. Such a dual response has not been observed in the present experiments and even when the extracts were allowed to remain in the bath for 15 minutes no secondary slow contraction was seen. The responses to a dose of extract were repeatable and no tachyphylaxis developed. However, not all preparations were sensitive to the dust extracts and about $10 \%$ of the animals gave strips of ileum that were refractory. Neither atropine sulphate $\left(10^{-7} \mathrm{~g}\right.$./1.), an antagonist of acetylcholine, nor lysergic acid diethylamide $\left(10^{-7}\right)$, an antagonist of 5-hydroxytryptamine, influenced the

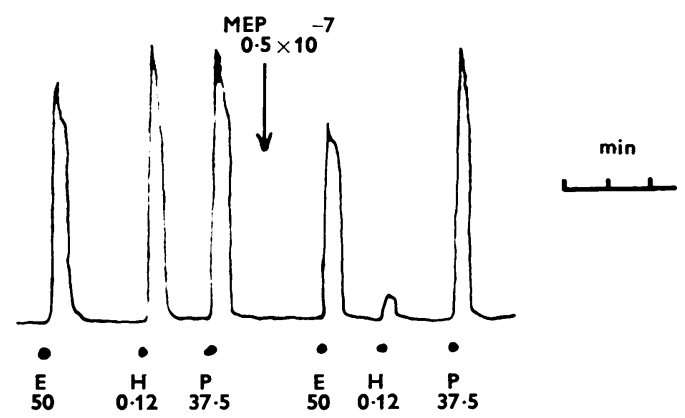

FIG. 1.-The action of extracts of cotton dust (E) and pericarp (P) on the isolated ileum of the guinea-pig. The doses of the extracts are expressed as their equivalent weight of dust (mg.). $\mathbf{H}=$ histamine ( $\mu$ g.). Mep = mepyramine. response of the tissue to dust. The antihistamine, mepyramine maleate $\left(0.5 \times 10^{-7}\right)$ had very little effect on the contraction produced by the extracts (Fig. 1). These results indicate that the contractor activity seen on the ileum is not due to acetylcholine, 5-hydroxytryptamine, or histamine. However, the contraction elicited by one extract from cotton dust (sample M) was reduced by $70 \%$ in the presence of mepyramine. This was investigated further by running paper chromatograms of $2 \mathrm{ml}$. portions of this extract in n-butanol saturated with $10 \%$ ammonia solution for 20 hours. The paper was dried and cut into strips $2 \mathrm{~cm}$. in width which were extracted by shaking with $2 \mathrm{ml}$. of Tyrode's solution. The activity of these extracts was tested on the isolated ileum. Contractor activity which was blocked by mepyramine was located with an $R_{F}$ of $0.50-0.54$. Histamine had a similar $R_{F}$ value when chromatographed in this way. Thus the presence of histamine in this dust sample (M) was confirmed.

Log dose-response curves for extracts prepared from cotton (E and Dutch), flax, and sisal were approximately parallel. The slopes of these lines were $+1 \cdot 37,+1.68,+1 \cdot 60$, and +1.46 respectively. This may indicate that the contractor activity in each of the dusts is mediated by a similar mechanism. When the activity of the extracts was assayed in terms of histamine, the cotton dusts were found to be the most active while jute dust was the least active (Table 1). Extracts of the pericarp and the stem of cotton bolls were as potent as those prepared from cotton dusts. As the active agent in the extracts is not histamine it is to be noted that assay in terms of histamine gives only an approximate measure of the levels of contractor activity in the 


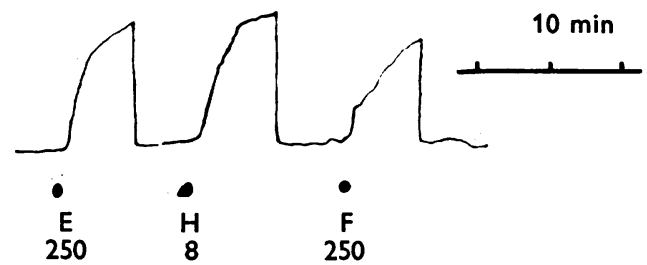

Fig. 2. - The action of vegetable dust extracts on the isolated tracheal muscle of the guinea-pig. The doses of the extracts are in mg. equivalents of dust. $\mathrm{H}=$ histamine $(\mu \mathrm{g}.) ; \mathrm{E}=$ cotton sample $\mathbf{E} ; \mathbf{F}=$ flax.

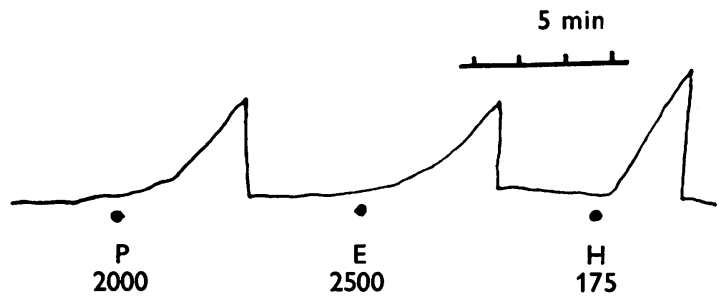

Fig. 3.-The action of cotton dust (E) and pericarp (P) extracts on isolated human bronchial muscle. The doses of the extracts are in mg. equivalents. $\mathrm{H}=$ histamine $(\mu \mathrm{g}$.$) .$

dusts and this accounts for the large standard error observed with a number of values. Nevertheless, the results give an indication of the relative levels of activity in different dusts. This was confirmed by comparing the height of contraction of an ileum preparation produced by a fixed dose of different dust extracts when the levels of activity in cotton (sample E), flax, sisal, and jute dusts were found to be in the ratio of $1: 0.72: 0.57: 0.19$ (the height of contraction was taken as a measure of potency). The figures from the assay rank the dusts of cotton, flax, and jute in the same order as the probable severity of byssinosis in the mills spinning these fibres; this lends support to the postulate that the contractor activity is important in explaining some of the symptoms of this condition. However, on this hypothesis sisal occupies an anomalous position as Gilson, Stott, Hopwood, Roach, McKerrow, and Schilling (1962) have not found any significant respiratory disturbances in the operatives in a sisal factory. From the limited number of chemical determinations made it can be seen that the activity of the dusts is correlated better with their carbohydrate content than with their nitrogen levels.

All the extracts that were active on the guinea-pig's ileum caused a slow contraction of the tracheal muscle preparation (Fig. 2). The speed of contraction was about the same as that elicited by histamine, but on washing out the bath the muscle relaxed much more slowly after the dust extracts than after histamine, i.e. 30 to 40 minutes as opposed to five minutes. This observation is of considerable interest since it has been observed that in man there is a slow development of changes in lung function and a slow recovery after inhalation of cotton dust. Assayed in terms of histamine, the extracts were 10 to 20 times as active as when assayed on the ileum (Table 1). This indicates that the contractor activity was not due to histamine; this is supported by the observation that the activity was not blocked by the presence of mepyramine in the muscle bath. Atropine also did not affect the activity of the dusts.

The action of extracts of cotton dust (Dutch and E), flax dust, and pericarp was examined on the isolated human bronchial muscle preparation. A contraction was elicited by each of the extracts (Fig. 3) which was not blocked by mepyramine. Again, the muscle relaxed only slowly on washing out the extract of the dust. No assays were made, but the four samples appeared to be equiactive.

The only extract to have a significant action on the rat duodenum and colon was that prepared from the material collected under the carding machines of the Dutch mill. A contraction was obtained when this extract was added to the bath containing these isolated muscle preparations. The action was reduced by lysergic acid diethylamide $\left(10^{-7}\right)$. When extracts of this sample were chromatographed in $n$-butanol saturated with $10 \%$ ammonia an active substance was detected with an $R_{F}$ value similar to that of 5-hydroxytryptamine (HT). This suggests that the plant debris from the card-room of this mill contained HT. Davenport and Paton (1962) have demonstrated that cotton dust may also contain this contractor substance. This finding is interesting as HT is known to occur in certain other plants. HT was not detected in the other dust extracts using these tissue preparations.

Any actions that the extracts had on the other isolated bath preparations listed in the "Methods" section above could be attributed to their potassium content.

(b) Perfused Preparations.-Histamine caused an increase in the amplitude of contraction of the perfused isolated heart of the guinea-pig which could be blocked by mepyramine. Extracts of cotton ( $E$ and Dutch) and flax dusts (equivalent to 125 to $250 \mathrm{mg}$. of dust) produced a similar effect which was not affected by mepyramine.

Extracts of cotton dust (samples E and Dutch, equivalent to $250 \mathrm{mg}$. of dust), injected into the pulmonary artery of the perfused lung of the guineapig, caused a rise in the bronchial pressure, which lasted about 30 minutes. Histamine and acetylcholine have similar actions which persist for about 10 minutes.

In the perfused hindquarters of the rat, English (sample E) and Dutch cotton dust and pericarp 
TABLE 2

HISTAMINE-RELEASING ACTIVITY OF COTTON DUST EXTRACTS IN PERFUSED HINDQUARTERS OF RAT

\begin{tabular}{l|c|c}
\hline \multicolumn{1}{c|}{ Sample } & $\begin{array}{c}\text { Dose } \\
\text { (equivalent to } \\
\text { mg. of dust) }\end{array}$ & $\begin{array}{c}\text { Histamine Released } \\
(\mu \mathrm{g} . / 100 \mathrm{~g} . \text { tissue } \\
\text { perfused) }\end{array}$ \\
\hline Cotton dust E & 175 & $12 \cdot 1$ \\
Cotton dust E & 350 & $5 \cdot 4$ \\
Cotton dust Dutch & 85 & $9 \cdot 1$ \\
Cotton dust Dutch & 175 & $13 \cdot 5$ \\
Cotton dust Dutch & 200 & $6 \cdot 7$ \\
Pericarp & 175 & $10 \cdot 4$ \\
Compound 48/80 & $2 \mu \mathrm{g}$. & 11.8 \\
\hline
\end{tabular}

extracts each caused the appearance of histamine in the perfusate without much change in perfusion rate (Table 2). The amount of perfusate collected in 90 minutes was considerably less when a high dose of the dust extract was injected than when smaller doses were employed. The lowered perfusion rate was probably caused by vasoconstriction and this may explain why the histamine released in these instances is smaller than that with lower doses. When compared with the histamine liberator, compound $48 / 80$, the activity of the dusts is not very strong. Extracts of the cotton linters and seeds were without action on this preparation.

\section{In vivo Experiments}

\section{(a) Animals}

RAT.-The response (pressor or depressor) of the blood pressure to injected histamine in the rat depends on the level of the blood pressure in the animal. Whatever the response to histamine, injections of extracts of cotton dust (Dutch and E), pericarp, bracts, and flax had a similar but more pronounced and prolonged action (Fig. 4). A subsequent injection of the extracts was less effective.

RABBIT.-Injection of these extracts into the rabbit gave similar results, e.g. an extract of Dutch dust equivalent to $100 \mathrm{mg}$. dust $/ \mathrm{kg}$. rabbit produced a fall in blood pressure equal to that given by a dose of $15 \mu \mathrm{g} . / \mathrm{kg}$. histamine. This action occurred 30 seconds after the injection and lasted for about four minutes.

CAT.-In the cat, intravenous injections of extracts of cotton dust (Dutch and E), pericarp, and bracts equivalent to 250 to $500 \mathrm{mg}$. dust $/ \mathrm{kg}$. cat elicited a hypotensive response 25 to 30 seconds later. This was similar to the response given to injections of compound $48 / 80(15 \mu \mathrm{g}$. $/ \mathrm{kg}$.). A second injection of the extracts was either less effective or gave no response. With one cat, however, a repeatable hypotensive response of short duration was obtained after injections of cotton dust (E $250 \mathrm{mg}$./ kg.) rather like that elicited by injected histamine. This response could not be reduced by mepyramine (1 mg./kg.).

These actions of the extracts on blood pressure may be explained by some sort of release process liberating an active agent, probably histamine. However, it is to be noted that while the cat is more sensitive than the rabbit and the rat to the action of compound 48/80, the cotton dust extracts are approximately equipotent in their histamine liberating actions in these three species. This indicates the difficulty of extrapolating these actions to the effects seen in man.

Dust extracts were prepared in Tyrode's solution and injected intraperitoneally into rats in a volume of $20 \mathrm{ml}$. Samples of peritoneal fluid were obtained 30 minutes later and assayed for histamine. Extracts of cotton dusts (Dutch and E), pericarp, and bracts caused the liberation of histamine but were only about one-thousandth the potency of compound 48/80 (Table 3). The histamine liberated was probably derived from the peritoneal mast cells as after dust extracts they did not stain well with toluidine blue. Thus the extracts are about one
Fig. 4.-The action of an extract of cotton dust from a Dutch mill on the blood pressure of the rat anaesthetized with pentobarbitone sodium (40 mg./kg. intraperitoneally). $\mathbf{H}$ $=$ histamine $(2.5 \mathrm{\mu g} . /$ kg.); $D=$ dust (200 mg. equivalents/kg.). Injections were made intravenously.

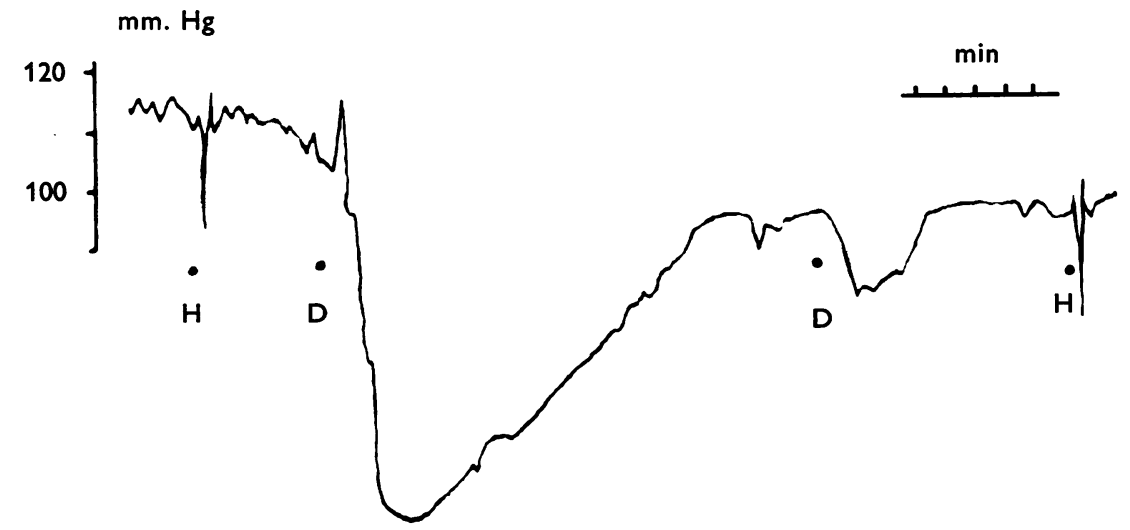


hundred times more active on this preparation than on the perfused hindquarters of the rat or the blood pressure of the cat when compared with $48 / 80$.

Intracutaneous injection of extracts of cotton dust (E and Dutch), flax, pericarp, and bracts caused an increase in permeability at the site of injection in the guinea-pig as detected by the infiltration of a blue dye. Cotton dust (E) and flax were equal in action to $1 \mu \mathrm{g}$. histamine/g. dust. Dutch dust, pericarp, and bracts had about twice this potency. The permeability effect of dust $\mathrm{E}$ was very slightly susceptible to a local antihistamine, triprolidine. Mepyramine injected with the extracts of Dutch dust and pericarp caused a 20 to $30 \%$ inhibition of activity. Histamine was rendered inactive by this procedure. These results suggest that there is a component present in the dusts causing an increase in cell permeability which does not act by histamine release.

Guinea-pigs exposed to an aerosol of an extract of cotton dust for two hours per day for six days showed no marked signs of dyspnoea. Each day a little coughing was observed in a few animals, but the lungs appeared normal on histological examination at the end of the week in all cases.

(b) In Man.-In contrast to the action on the guinea-pig's skin, application of saline extracts of cotton dust ( $E$ and Dutch) and pericarp on the forearm of six volunteers for one minute produced no reaction when observation was made periodically over 24 hours. All the subjects reacted to $0.01 \%$ histamine. These results are not in agreement with those of Prausnitz (1936) and Cayton, Furness, and Maitland (1952) who found that cotton dust extracts gave rise to a cutaneous reaction in man. However, these workers injected the extracts intradermally and this may explain the difference.

\section{Bacterial Action in Extracts of Cotton Dust}

During the course of experiments on the isolated ileum of the guinea-pig it was observed that extracts of cotton dust $(\mathrm{E})$ allowed to stand at room temperature for 24 to 48 hours showed signs of bacterial growth. Such extracts were found to have increased in contractor activity by up to $100 \%$. This activity was sensitive to mepyramine and on chromatography of the extracts a contractor substance having an $R_{F}$ value similar to that of histamine was detected. By plating out the extract on agar-peptone two types of bacterial colony were isolated which were both found to be coliform organisms. Further identification was not carried out. When these bacteria were incubated in either saline, Tyrode's solution, or peptone broth for up to three days no smooth muscle contractor activity was formed. However,
TABLE 3

HISTAMINE-RELEASING ACTIVITY OF DUST EXTRACTS IN RAT PERITONEUM

\begin{tabular}{l|c|c}
\hline \multicolumn{1}{c|}{ Extracts } & $\begin{array}{c}\text { Dose } \\
\text { (equivalent to } \\
\text { mg. of dust) }\end{array}$ & $\begin{array}{c}\text { Histamine Released } \\
\text { ( } \mu \text { g./mg. } \\
\text { peritoneal fiuid) }\end{array}$ \\
\hline Cotton dust E & 500 & $0 \cdot 13$ \\
Cotton dust E & 1,500 & $0 \cdot 28$ \\
Cotton dust E & 2,000 & $0 \cdot 44$ \\
Cotton dust Dutch & 500 & $0 \cdot 18$ \\
Cotton dust Dutch & 1,000 & $0 \cdot 26$ \\
Pericarp & 500 & $0 \cdot 16$ \\
Bracts & 500 & $0 \cdot 09$ \\
Compound 48/80 & $20 \mu \mathrm{g}$. & 0.36 \\
\hline
\end{tabular}

All extracts were injected in $20 \mathrm{ml}$. of Tyrode's solution.

if the organisms were added to extracts of cotton dusts (sample E) which had been sterilized by filtration an increase in contractor power was found 24 hours after incubation at $27^{\circ} \mathrm{C}$. These results suggested that the bacteria were able to form histamine from some substrate present in the dust extract. Both micro-organisms were able to form histamine from histidine when incubated in Tyrode's solution containing this amino acid. However, histidine could not be detected chromatographically in the dust extracts and there was no evidence that proteolysis took place. The source of the histamine, therefore, remains unaccounted for.

It was interesting to see whether this phenomenon could be detected in cotton dust exposed at high humidities for several days, i.e. conditions that could be expected in a cotton mill during week-ends. If such an action were shown to take place it would provide a possible explanation of the "Monday symptoms", the increased histamine content of the dust on Monday giving rise to a higher incidence of respiratory disturbances. Cotton dust (E) in $5 \mathrm{~g}$. portions was spread in thin layers and exposed for up to three days in atmospheres of relative humidities between 40 and $70 \%$ at temperatures of 18,27 , and $37^{\circ} \mathrm{C}$. Humidity was controlled by means of saturated salt solutions (O'Brien, 1948). The dust was then extracted as described previously. In none of the dust samples so treated was there any increase in smooth muscle contractor power.

The only viable micro-organism that was obtained from extracts of the pericarp and bracts was a yeast. Its growth in these extracts did not affect their contractor activity.

\section{Chemical Properties of Smooth Muscle Contractor Substance in Cotton Dust (Sample E)}

Solubility.-The contractor activity was equally extracted by distilled water, $0.9 \%$ saline, Tyrode's solution, and Krebs' solution. The activity was soluble in diethylene glycol but not in methanol, ethanol, isopropanol, $n$-butanol, acetone, benzene, or chloroform. 
Stability.-The activity was destroyed by incineration which indicates that it is organic. Extracts were stable at $110^{\circ} \mathrm{C}$. for 30 minutes. After two hours at this temperature there was a loss of $25 \%$ of the activity. Extracts could be autoclaved at $20 \mathrm{lb}$./sq. in. for 30 minutes without loss of either contractor or histamine-liberating action. This is in accord with the findings of Antweiler (1960). Activity was not destroyed by freeze-drying nor by storage of the extracts at $-15^{\circ} \mathrm{C}$. for at least three months.

In $1.5 \mathrm{~N}$ sodium hydroxide and hydrochloric acid respectively activity was completely destroyed at $110^{\circ} \mathrm{C}$. for 30 minutes. At room temperature there was a partial loss of activity after 30 mintues; $70 \%$ loss in alkali and $30 \%$ in acid.

Fractionation.-Activity was almost completely dialysed in eight hours, when an extract of the dust was enclosed in a collodion bag and immersed in four times its volume of distilled water. When cellulose film dialysis tubing was used only about $60 \%$ of the activity was dialysed in eight hours. This difference may reflect a different pore size in the collodion and cellulose film membranes but the results indicate that the contractor substance is probably a small molecule.

The contractor activity remained at the point of application when extracts of the dust were chromatographed on Whatman No. 1 paper using the following systems; butanol/acetic acid/water, butanol/ ammonia, isopropanol/water, methanol/petroleum ether. During electrophoresis in phosphate buffer $p \mathrm{H} 7.4$ (three and a half hours and $6 \mathrm{v} . / \mathrm{cm}$.) the contractor activity moved towards the anode indicating that there was a negative charge on the molecule. It is interesting to note that Davenport and Paton (1962) found that the particulate matter obtained by centrifuging dust extracts was negatively charged and could also contract the isolated ileum.

A preliminary attempt was made to isolate the contractor component. A solution of sodium benzoate was mixed with the extract and sufficient hydrochloric acid was added to precipitate benzoic acid. After centrifuging, the benzoic acid was dissolved in acetone leaving behind an insoluble residue derived from the dust extract which had been co-precipitated with the acid. This material was centrifuged down and dissolved in Tyrode's solution. The supernatant from the preliminary co-precipitation with benzoate was adjusted to $p \mathrm{H} 7 \cdot 4$. Both fractions were found to be inactive when tested on the isolated ileum of the guinea-pig. Thus this procedure completely destroyed the activity present in the extract.

Aqueous extracts of the dust were mixed with varying amounts of acetone and kept overnight at $4^{\circ} \mathrm{C}$. Any precipitate was then centrifuged down and dissolved in Tyrode's solution. The activity of the solution was tested on isolated smooth muscle preparations. Acetone 25 and $50 \%$ yielded small amounts of precipitates which were inactive. At a concentration of $75 \%$ acetone a fraction was obtained which was without action on the ileum but which caused contraction of the isolated colon of the rat. The significance of this is not clear. If the contractor activity is insoluble in acetone, as was found in the solubility experiments, the "acetone precipitate" should have been active on the ileum. Failure to obtain this indicates that the contractor substance is very sensitive to certain chemical agents. This is known to occur with other biologically active agents such as polypeptide hormones.

Pernis et al. (1961) have suggested that some of the symptoms of byssinosis may be caused by the presence of bacterial endotoxins in cotton dust, so it was decided to attempt a fractionation of the dust by a method used for extraction of endotoxins (Maclennan, 1960). This procedure involves extracting the material with phenol and subsequently removing this compound from the extract. The isolated product was brown in colour and was soluble in water; $1 \mathrm{~g}$. of dust yielded $40 \mathrm{mg}$. of the isolate which gave a strong positive anthrone test for the presence of carbohydrate. The material was reconstituted in Tyrode's solution so that it was of equivalent strength to an untreated cotton extract. This solution caused a contraction of the isolated ileum which was about half the height of the response to the untreated extract. The contraction was of a similar nature to that given by normal dust extracts. Bracts were extracted by the same method and $1 \mathrm{~g}$. yielded about $50 \mathrm{mg}$. of a similar material which also caused the ileum to contract. In both cases only a small amount of the isolated material can possibly be derived from the bacterial content of the sample. From the figures given by Antweiler (1961) the endotoxin content of bacteria is about $1 \%$ of their dry weight. Thus $4 \mathrm{~g}$. of bacteria would be required to yield $40 \mathrm{mg}$. of endotoxin, a weight in excess of the cotton dust and bracts used for extraction. In addition, it seems unlikely that the bacterial content of the bracts can represent but a minute fraction of their total weight. Such a material isolated from plant sources does not appear to have been described previously and the activity of this phenol extract is being further investigated.

\section{DISCUSSION}

All the dusts that have been examined contain a smooth muscle contractor substance, a finding which is in agreement with the results of Davenport 
and Paton (1962). Those dusts that have been tested by the appropriate methods (cotton sample $\mathrm{E}$ and Dutch flax) were found to possess histamineliberating activity and a component causing increase of cell permeability. Previously, cotton dust from a Dutch mill has been shown by Antweiler (1960) to have histamine-liberating activity. On the present experiments one dust sample (M) was found to contain histamine and another sample (shreds from a Dutch card-room) to contain 5-hydroxytryptamine. Thus cotton dust is a pharmacologically heterogeneous mixture of activities the relative proportions of which may vary considerably. This makes the evaluation of such actions in relation to byssinosis difficult.

The contractor activity which is observed on the isolated ileum and trachea of the guinea-pig is not identical with any other known pharmacological agent. As a repeatable response of these preparations is obtainable, the action does not appear to be due to a liberation of histamine. Only certain histamine liberators have an action on the gut, e.g. snake venoms, and the response elicited is a slow contraction. Tachyphylaxis to these compounds also quickly develops. Endotoxins have similar actions to these histamine liberators. The chemical tests performed are only preliminary but the results obtained are not inconsistent with the view that the contractor substance may be of a polysaccharide nature. This is supported by the parallelism of contractor activity with carbohydrate but not with nitrogen content of the dust extracts. It is interesting that Davenport and Paton (1962) have found that proteolytic enzymes do not affect this activity. The smooth muscle contractor activity found in the dusts from phylogenetically different plants has similar actions in each of the preparations examined and, therefore, may be of a similar nature. The approximate parallelism of dose-response curves constructed by reference to their activity on the isolated ileum is in accordance with this view. From the results presented here it is not possible to determine whether the permeability factor, the smooth muscle contractor, and the histamine-releasing activity are the property of a common molecule or belong to different moieties, though by comparison with Antweiler's (1960) work the latter two activities have certain chemical similarities.

Two main difficulties are encountered when an attempt is made to relate these observations to the symptoms of byssinosis. First, there are no data relating the doses employed in the pharmacological experiments to the amounts of dust inhaled by cotton workers and secondly, there is uncertainty in extrapolating the results of experiments with isolated preparations to man. The evidence for these actions being important in the human subject is, therefore, indirect and a conclusive demonstration that such actions are relevant will require a long-term analysis of the effects of inhalations of dust extracts and of various fractions prepared from dust.

Of all the activities described, that of histamine release would best explain the "Monday symptoms" experienced by cotton workers. Indeed, Bouhuys et al. (1960) have shown that inhalations of dust extracts are capable of giving rise to some of the signs of histamine release. However, the significance of this action seems small since the activity of the dust is very weak when compared with compound 48/80, and Davenport and Paton (1962) have pointed out that nonantigenic histamine liberators are rather inactive in producing bronchoconstriction. That the "Monday symptoms" can be explained by an increase in the histamine content of the dust due to bacterial action is seen to be incorrect.

The actions of dust extracts are not typical of those of endotoxins and it is very doubtful if there is a sufficiently large concentration of these bacterial products in the dust to be effective. This is certainly true in the case of the pericarp and bracts of the cotton boll which must be relatively free from bacteria but nevertheless possess high pharmacological activity. Antweiler (1961) has drawn a similar conclusion and has discounted the hypothesis of Pernis et al.(1961) that endotoxins are responsible for some of the symptoms of byssinosis.

Dusts from mills where byssinosis is known to occur all contain a smooth muscle contractor substance. As it is able to cause contraction of isolated human bronchial muscle it is possible that, on inhalation, it would give rise to bronchoconstriction in man. As the activity is water-soluble it probably acts locally in the lungs but it could also act systemically after absorption through the bronchial walls. The permeability-increasing factor might cause bronchial oedema. The slow relaxation of bronchial muscle after contraction to dust and the oedema may explain the slow recovery of lung function observed in man after the inhalation of cotton dust. Not only the presence of this agent in the dusts but also the relation of incidence of byssinosis to the relative activity of the dusts make attractive the hypothesis that the contractor substance is a factor concerned in byssinosis. Although the relatively high activity of sisal is not in accord with this view, it is to be remembered that only one sample of this dust, which was not an airborne sample, has been examined, and that subsequent samples may be found to contain less contractor activity. To substantiate this hypothesis it is evident that further samples from various mills must be examined to observe if this order of activity of the different dusts always obtains. 
In conclusion, it is suggested that the smooth muscle contractor activity present in the vegetable dusts examined is an important factor in byssinosis. If this hypothesis is correct, biological assay of the activity of dusts in terms of a standard extract of dust should give an indication of the hazard to which the operatives in these mills are exposed. An investigation is being made of airborne samples of dust from mills spinning different fibres in order to relate the biological activity of the dusts with the proportion of subjects with symptoms of byssinosis.

I wish to acknowledge gifts of compound 48/80 from Dr. A. C. White, Wellcome Research Laboratories, Kent, and samples of Dutch cotton dust from Dr. H. Antweiler. I wish to thank Professor A. A. Miles for obtaining the results of the permeability factor with cotton dust (E) and Mr. H. S. Harley, Sully Hospital, Glam., for specimens of human bronchial tissue. I thank the following for their advice and the useful discussions we have had during the course of this work: Professors W. D. M. Paton and R. S. F. Schilling, Drs. J. C. Gilson and C. B. McKerrow and Miss A. Davenport. Part of this work was performed during the tenure of a personal grant from the Medical Research Council at the Welsh National School of Medicine.

\section{REFERENCES}

Antweiler, H. (1960). Arch. Gewerbepath. Gewerbehyg., 17, 574. (1961). Brit. J. industr. Med., 18, 130.

Arunlakshana, O., and Schild, H. O. (1959). Brit. J. Pharmacol., 14, 48.

Ashwell, G. (1957). Methods in Enzymology, ed. S. P. Colowick and N. O. Kaplan, Vol. 3, p. 84. Academic Press, New York.

Bouhuys, A., Lindell, S. E., and Lundin, G. (1960). Brit. med. J., 1,

Cayton, H. R., Furness, G., and Maitland, H. B. (1952). Brit. J. industr. Med., 9, 186.

Davenport, A., and Paton, W. D. M. (1962). ibid., 19, 19.

Fawcett, D. W. (1954). J. exp. Med., 100, 217.

Feldberg, W., and Mongar, J. L. (1954). Brit. J. Pharmacol., 9, 197.

Gaddum, J. H., and Horton, E. W. (1959). ibid., 14, 117.

Gilson, J. C., Stott, H., Hopwood, B. E. C., Roach, S. A., McKerrow, C. B., and Schilling, R. S. F. (1962). Brit. J. industr. Med., 19,9 .'

Hawkins, D. F., and Schild, H. O. (1951). Brit. J. Pharmacol., 6, 682.

McKerrow, C. B., McDermott, M., Gilson, J. C., and Schilling, R. S. F. (1958). Brit. J. industr. Med., 15, 75.

R.S. F. (1958), Brit. J. industr. Med., 15,

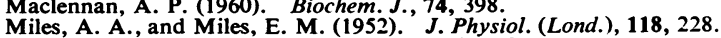

O'Brien, F. E. M. (1948). J. sci. Instrum., 25, 73.

Pernis, B., Vigliani, E. C., Cavagna, C., and Finulli, M. (1961). Brit. J. industr. Med., 18, 120 Prausnitz, C. (1936). Spec. Rep. Ser. med. Res. Coun. (Lond.), No. 